\title{
Retraction Note To: The relationship between subclinical thyroid dysfunction and the risk of fracture or low bone mineral density: a systematic review and meta-analysis of cohort studies
}

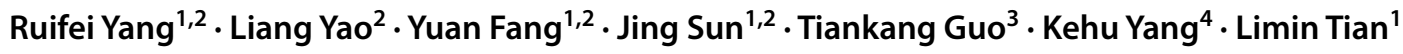 \\ Published online: 2 August 2019 \\ (c) The Japanese Society Bone and Mineral Research and Springer Japan KK, part of Springer Nature 2019
}

\section{Retraction Note To: J Bone Miner Metab (2018) 36:209-220 https://doi.org/10.1007/ s00774-017-0828-5}

The editors have retracted this article [1] because it shows significant overlap with a publication by Blum et al. [2] Limin Tian does not agree to this retraction. All the other authors have not responded to any correspondence from the editor about this retraction.

[1] Yang R, Yao L, Fang Y, Sun J, Guo T, Yang K, and Tian. L J Bone Miner Metab (2018) 36: 209. https://doi. org/10.1007/s00774-017-0828-5
[2] Blum MR, Bauer DC, Collet TH, Fink HA, Cappola AR, Da Costa BR, Wirth CD, Peeters RP, Åsvold BO, Den Elzen WP, Luben RN. Subclinical thyroid dysfunction and fracture risk: a meta-analysis. JAMA. 2015 May 26;313(20):2055-65.

The original article can be found online at https://doi.org/10.1007/ s00774-017-0828-5.

Kehu Yang

kehuyangebm2006@126.com

$\checkmark$ Limin Tian

tlm6666@sina.com

1 Department of Endocrinology, The Gansu Provincial Hospital, Donggang West Road, Lanzhou 730000, Gansu, People's Republic of China

2 Institution of Clinical Research and Evidence Based Medicine, The Gansu Provincial Hospital, Donggang West Road, Lanzhou 730000, Gansu, People's Republic of China

3 Department of General Surgery, The Gansu Provincial Hospital, Donggang West Road, Lanzhou 730000, Gansu, People's Republic of China

4 Evidence Based Medicine Center, School of Basic Medical Sciences, Lanzhou University, Lanzhou 730000, People's Republic of China 